\title{
Effectiveness of new plant protection products in the protection of Chinese aster against fungal diseases
}

\author{
Skuteczność nowych preparatów \\ w ochronie astra chińskiego przed mikozami
}

\author{
Jacek Nawrocki
}

\section{Summary}

Field experiments were carried out in 2010 and 2011 on three dwarf cultivars of China-aster: Duszek, Skrzat and Srebrzysta Gwiazdka. The following biological plant protection products were applied: Polyversum WP (Pythium oligandrum), Trifender WP (Trichoderma asperellum) and biotechnical product HF-Mycol (fennel oil - 23.08\%) and Prev-B2 (D-limonene - 4.2\%, boron - 2.1\%). Fungicide Amistar 250 SC (azoxystrobin $250 \mathrm{~g} / \mathrm{l}$ ) was used as a standard, and unprotected plants were untreated control. Health conditions of leaves, stems and inflorescences were studied during the vegetation season. Collected data included number of wilting and dying plants. Mycological analyzes were also carried out on infested plant parts. Amistar 250 SC and Polyversum WP used preventively in protection of aster wilt showed the highest effectiveness. They also limited the decay of whole plants. Products Amistar 250 SC and Prev-B2 efficiently inhibited the development of dieback of entire inflorescences. Prophylactic spraying with Amistar 250 SC, Prev-B2 and Polyversum WP effectively limited the occurrence of lesions on the leaves and shoots in comparison with plants from control treatment.

Key words: preparations containing natural substances, biological plant protection products, Chinese aster, health conditions of plants

\section{Streszczenie}

Doświadczenia polowe przeprowadzono w latach 2010 i 2011 na 3 odmianach karłowych astra chińskiego: Duszek, Skrzat i Srebrzysta Gwiazdka. Zastosowano preparaty biologiczne: Polyversum WP (Pythium oligandrum) i Trifender WP (Trichoderma asperellum) oraz preparaty biotechniczne: HF-Mycol (olejek fenkułowy - 23,08\%) i Prev-B2 (olejek pomarańczowy - 4,2\%, bor - 2,1\%). Jako standardowy fungicyd użyto Amistar 250 SC (azoksystrobina $250 \mathrm{~g} / \mathrm{l}$ ). Kontrolę stanowiły rośliny niechronione. Podczas wegetacji oceniano zdrowotność liści, pędów oraz kwiatostanów. Odnotowano ilość więdnących i zamierających roślin. Przeprowadzono także analizy mikologiczne porażonych części roślin. Najskuteczniejszymi preparatami w ochronie astra przed pasożytniczym więdnięciem okazały się zastosowane profilaktycznie: Amistar 250 SC oraz Polyversum WP, które równocześnie ograniczały zamieranie całych roślin. Preparaty Amistar 250 SC oraz Prev-B2 skutecznie hamowały rozwój zamierania całych kwiatostanów. Profilaktyczne opryskiwania środkami Amistar 250 SC, Pev-B2 i Polyversum WP skutecznie ograniczały występowanie zmian chorobowych zarówno na liściach, jak i pędach w porównaniu z roślinami z kombinacji kontrolnej.

Słowa kluczowe: preparaty zawierające naturalne substancje, środki biologiczne, aster chiński, zdrowotność roślin

\footnotetext{
Uniwersytet Rolniczy im. Hugona Kołłątaja w Krakowie

Katedra Ochrony Roślin

Al. 29 Listopada 54, 31-425 Kraków

j.nawrocki@ogr.ur.krakow.pl
} 


\section{Wstęp / Introduction}

W Polsce najgroźniejszą chorobą astra chińskiego nadal pozostaje pasożytnicze więdnięcie roślin powodowane przez Fusarium oxysporum f. sp. callistephi, a także przez grzyby rodzaju Verticillium. Sprawcą zamierania astrów dość często jest Rhizoctonia solani. Bardzo groźnym patogenem, zwłaszcza dla kwiatostanów i młodych pędów, jest sprawca szarej pleśni - Botrytis cinerea (Orlikowski i Saniewska 1988; Saniewska 1991; Horst 2008). W celu ograniczenia strat powodowanych przez patogeny atakujące liście, pędy i kwiatostany astra chińskiego zaleca się stosowanie opryskiwań standardowymi fungicydami, niestety co roku jest coraz mniej preparatów zarejestrowanych do ochrony astra. Zbyt mała rotacja substancji chemicznych może być przyczyną mniejszej skuteczności ochronnych zabiegów chemicznych. Większość fungicydów testowanych przez Saniewską (1993) nie jest już dostępna do stosowania. Należy poszukiwać nowych preparatów biologicznych i zawierających substancje naturalne, które będą skutecznie ograniczać rozwój groźnych patogenów, a zarazem nie będą stanowić zagrożenia dla środowiska naturalnego (Saniewska 2001, 2006).

Celem pracy było określenie skuteczności wybranych preparatów biologicznych i zawierających substancje naturalne zastosowanych profilaktycznie $\mathrm{w}$ okresie wegetacji do ochrony astra chińskiego przed chorobami grzybowymi.

\section{Materiały i metody / Materials and methods}

Doświadczenia polowe przeprowadzono w latach 2010 i 2011 na glebie intensywnie uprawianej ogrodniczo, na 3 odmianach karłowych astra chińskiego: Duszek, Skrzat i Srebrzysta Gwiazdka. W badaniach zastosowano preparaty biologiczne: Polyversum WP $\left(10^{6}\right.$ oospor Pythium oligandrum w $1 \mathrm{~g}) \mathrm{W}$ stężeniu $0,05 \%$ i Trifender WP $\left(5 \times 10^{8}\right.$ zarodników Trichoderma asperellum w $\left.1 \mathrm{~g}\right)$ w stężeniu $0,15 \%$ oraz preparaty zawierające substancje naturalne: HF-Mycol (olejek fenkułowy - 23,08\%) w dawce $0,4 \%$ i Prev-B2 (d-limonen $-4,2 \%$, bor $-2,1 \%$ ) w stężeniu 0,3\%. Jako standardowy fungicyd użyto Amistar 250 SC (azoksystrobina $250 \mathrm{~g} / \mathrm{l}$ ) w stężeniu 0,1\%. Rośliny opryskiwano 4-krotnie w ciągu okresu wegetacji. Trifender WP wprowadzano do gleby podlewając rośliny. Kontrolę stanowiły rośliny niechronione. Każdą kombinację stanowiło 25 roślin w trzech powtórzeniach. Podczas kwitnienia badano zdrowotność liści, pędów oraz kwiatostanów. Odnotowano ilość więdnących i zamierających roślin. Przeprowadzono także analizy mikologiczne porażonych części roślin. Nasilenie objawów chorobowych szacowano w skali od 1 do 4 . Z uzyskanych danych obliczano indeks porażenia (Nawrocki 2008). Wyniki zostały opracowane statystycznie, istotność różnic oceniano na podstawie testu Duncana przy poziomie istotności 5\%, z zastosowaniem dwuczynnikowej analizy wariancji - odmiana i preparat.

\section{Wyniki i dyskusja / Results and discussion}

Podczas wegetacji zaobserwowano na astrach dość licznie występujące objawy więdnięcia i zamierania całych roślin. Najwięcej zamierających astrów zaobserwowano wśród roślin odmiany Duszek, a najmniej u odmiany Srebrzysta Gwiazdka w obu latach obserwacji (tab. 1). Istotny wpływ odporności odmiany astra na Fusarium oxysporum f. sp. callistephi (Foc) stwierdzili Saniewska i wsp. (1992), którzy określili odmiany Skrzat i Srebrzysta Gwiazdka jako średnio odporne na porażenie $F$. oxysporum. Podobnie Necas i Kobza (2008) wskazują na istotną rolę odporności odmiany jako czynnika ograniczającego porażenie przez $F$. oxysporum. W 2010 r. najmniej zamierających roślin zanotowano $\mathrm{w}$ kombinacjach $\mathrm{z}$ preparatem Amistar 250 SC oraz Polyversum WP, podobnie było w 2011 r. niezależnie od badanej odmiany. Preparat

Tabela 1. Wpływ zastosowanych preparatów na liczbę zamarłych roślin [\%]

Table 1. Effect of applied plant protection products on the number of dead plants [\%]

\begin{tabular}{l|c|c|c|c|c|c}
\hline \multirow{2}{*}{$\begin{array}{c}\text { Kombinacja } \\
\text { Treatment }\end{array}$} & \multicolumn{4}{|c|}{2010} & \multicolumn{2}{c}{2011} \\
\cline { 2 - 7 } & Duszek & Skrzat & $\begin{array}{c}\text { Srebrzysta } \\
\text { Gwiazdka }\end{array}$ & Duszek & $\begin{array}{c}\text { Srebrzysta } \\
\text { Gwiazdka }\end{array}$ \\
\hline $\begin{array}{l}\text { Azoksystrobina } \\
\text { Azoxystrobin }\end{array}$ & $11,57 \mathrm{abc}$ & $8,16 \mathrm{abc}$ & $4,53 \mathrm{a}$ & $13,01 \mathrm{ab}$ & $11,33 \mathrm{ab}$ & $7,03 \mathrm{a}$ \\
\hline $\begin{array}{l}\text { Olejek fenkułowy } \\
\text { Fennel oil }\end{array}$ & $21,62 \mathrm{c}$ & $16,36 \mathrm{bc}$ & $19,31 \mathrm{bc}$ & $14,21 \mathrm{ab}$ & $16,36 \mathrm{ab}$ & $17,31 \mathrm{ab}$ \\
\hline $\begin{array}{l}\text { Pythium } \\
\text { oligandrum }\end{array}$ & $15,47 \mathrm{abc}$ & $11,57 \mathrm{abc}$ & $6,49 \mathrm{ab}$ & $16,35 \mathrm{ab}$ & $13,01 \mathrm{ab}$ & $8,16 \mathrm{a}$ \\
\hline $\begin{array}{l}\text { D-limonen } \\
\text { D-limonene }\end{array}$ & $16,36 \mathrm{bc}$ & $19,31 \mathrm{bc}$ & $13,01 \mathrm{abc}$ & $26,20 \mathrm{~b}$ & $19,31 \mathrm{ab}$ & $19,64 \mathrm{ab}$ \\
\hline $\begin{array}{l}\text { Trichoderma } \\
\text { asperellum }\end{array}$ & $19,31 \mathrm{bc}$ & $16,36 \mathrm{bc}$ & $13,01 \mathrm{abc}$ & $16,35 \mathrm{ab}$ & $16,36 \mathrm{ab}$ & $13,01 \mathrm{ab}$ \\
\hline $\begin{array}{l}\text { Kontrola } \\
\text { Control }\end{array}$ & $20,92 \mathrm{c}$ & $18,27 \mathrm{bc}$ & $15,47 \mathrm{abc}$ & $23,18 \mathrm{~b}$ & $25,72 \mathrm{~b}$ & $19,31 \mathrm{ab}$ \\
\hline
\end{tabular}

Średnie oznaczone tą samą literą w obrębie poszczególnych odmian nie różnią się istotnie (5\%) według testu Duncana, dla każdego roku osobno Means followed by the same letter do not differ at $5 \%$ level of significance Duncans's multiple range test, for each year separately 
Tabela 2. Wpływ zastosowanych preparatów na liczbę porażonych kwiatostanów [\%]

Table 2. Effect of applied plant protection products on the number of infected inflorescens [\%]

\begin{tabular}{l|c|c|c|c|c|c}
\hline \multirow{2}{*}{$\begin{array}{c}\text { Kombinacja } \\
\text { Treatment }\end{array}$} & \multicolumn{4}{|c|}{2010} & \multicolumn{2}{c}{2011} \\
\cline { 2 - 7 } & Duszek & Skrzat & $\begin{array}{c}\text { Srebrzysta } \\
\text { Gwiazdka }\end{array}$ & Duszek & $\begin{array}{c}\text { Srebrzysta } \\
\text { Gwiazdka }\end{array}$ \\
\hline $\begin{array}{l}\text { Azoksystrobina } \\
\text { Azoxystrobin }\end{array}$ & $6,49 \mathrm{a}$ & $10,00 \mathrm{abc}$ & $6,49 \mathrm{a}$ & $11,57 \mathrm{ab}$ & $10,93 \mathrm{ab}$ & $8,16 \mathrm{a}$ \\
\hline $\begin{array}{l}\text { Olejek fenkułowy } \\
\text { Fennel oil }\end{array}$ & $17,29 \mathrm{def}$ & $16,60 \mathrm{def}$ & $14,76 \mathrm{cdef}$ & $18,82 \mathrm{bc}$ & $14,76 \mathrm{abc}$ & $13,01 \mathrm{abc}$ \\
\hline $\begin{array}{l}\text { Pythium } \\
\text { oligandrum }\end{array}$ & $18,27 \mathrm{ef}$ & $13,24 \mathrm{bcde}$ & $16,60 \mathrm{def}$ & $13,97 \mathrm{abc}$ & $15,52 \mathrm{abc}$ & $14,39 \mathrm{abc}$ \\
\hline $\begin{array}{l}\text { D-limonen } \\
\text { D-limonene }\end{array}$ & $8,15 \mathrm{ab}$ & $11,57 \mathrm{bcd}$ & $10,00 \mathrm{abc}$ & $12,97 \mathrm{abc}$ & $11,57 \mathrm{ab}$ & $10,93 \mathrm{ab}$ \\
\hline $\begin{array}{l}\text { Trichoderma } \\
\text { asperellum }\end{array}$ & $12,26 \mathrm{bcde}$ & $14,76 \mathrm{cdef}$ & $13,24 \mathrm{bcde}$ & $23,28 \mathrm{c}$ & $15,52 \mathrm{abc}$ & $17,00 \mathrm{abc}$ \\
\hline $\begin{array}{l}\text { Kontrola } \\
\text { Control }\end{array}$ & $20,27 \mathrm{f}$ & $18,27 \mathrm{ef}$ & $18,27 \mathrm{ef}$ & $21,62 \mathrm{c}$ & $23,01 \mathrm{c}$ & $18,82 \mathrm{bc}$ \\
\hline
\end{tabular}

Średnie oznaczone tą samą literą w obrębie poszczególnych odmian nie różnią się istotnie (5\%) według testu Duncana, dla każdego roku osobno Means followed by the same letter do not differ at $5 \%$ level of significance Duncans's multiple range test, for each year separately

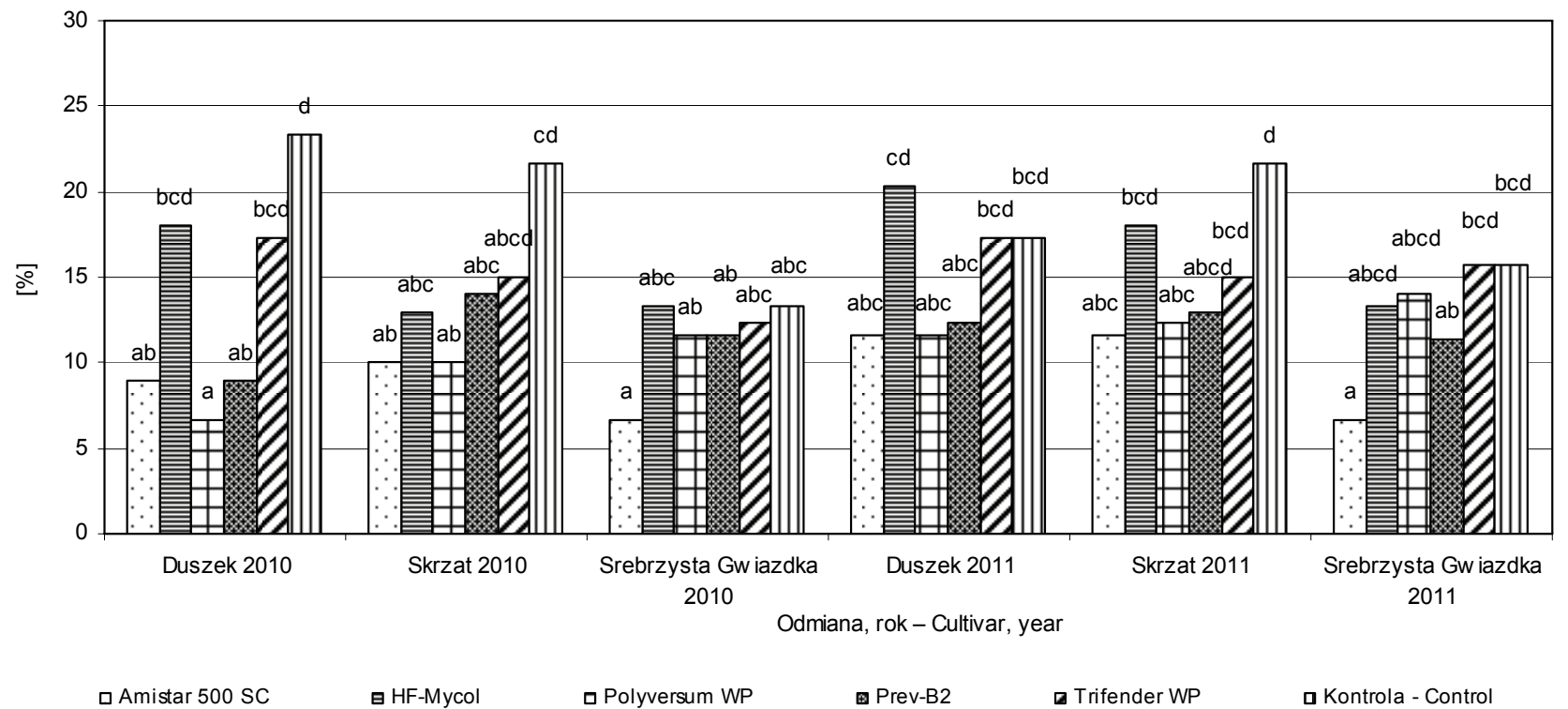

Średnie oznaczone tą samą literą w obrębie poszczególnych odmian nie różnią się istotnie (5\%) według testu Duncana, dla każdego roku osobno Means followed by the same letter do not differ at $5 \%$ level of significance Duncans's multiple range test, for each year separately

Rys. 1. Wpływ stosowania biopreparatów i preparatów zawierających substancje naturalne na ograniczenie indeksów porażenia liści i pędów astra

Fig. 1. Effect of using biopreparations and products containing natural substances to reduce the infestation indices aster leaves and stems

Prev-B2 był całkowicie nieskuteczny, powodował nawet zwiększenie liczby zamierających roślin w porównaniu do kontroli u odmiany Skrzat w 2010 r. i u odmiany Duszek w 2011 r. Analiza statystyczna uzyskanych wyników nie potwierdziła istotnego wpływu zastosowanych preparatów na ograniczenie liczby zamarłych roślin. Dużą skuteczność organizmu grzybopodobnego Pythium oligandrum w ochronie astra przed fuzarioza, w doświadczeniach wazonowych potwierdziła Saniewska (2001). Omawiane badania polowe nie wykazały skuteczności grzyba Trichoderma asperellum $\mathrm{w}$ ochronie przed fuzariozą naczyniową astra, choć Segarra i wsp. (2010) opisują korzystne oddziaływanie tego mikopasożyta $\mathrm{w}$ ochronie pomidora przed fuzariozą. Podczas przeprowadzonych doświadczeń nie stwierdzono istotnego wpływu olejku fenkułowego (HFMycol) na ograniczenie więdnięcia i zamierania astrów, chociaż Seema i Devaki (2010) wykazali skuteczność tego olejku, w warunkach in vitro, w ograniczeniu wzrostu i rozwoju Rhizoctonia solani, potencjalnego sprawcy zamierania astrów.

Rozpatrując zdrowotność kwiatostanów, można zaobserwować, że w obu latach badań, niezależnie od odmiany, 
najskuteczniej chroniły przed porażeniem kwiatostanów przez patogeny grzybowe preparaty Amistar $250 \mathrm{SC}$ oraz Prev-B2 (tab. 2). Analiza statystyczna potwierdziła istotny korzystny wpływ obu środków na zdrowotność kwiatostanów astra. Pozostałe testowane preparaty nie wpłynęły istotnie na ograniczenie liczby porażonych kwiatostanów w porównaniu z kontrolą. Skuteczność d-limonenu (PrevB2) w ograniczaniu rozwoju Botrytis cinerea w warunkach in vitro potwierdzaja badania Wilson i wsp. (1997).

Biorąc pod uwagę wyniki analiz zdrowotności liści i pędów astra, można stwierdzić, że istotny wpływ na zdrowotność części zielonych astrów, oprócz zastosowanych preparatów, ma także odmiana (rys. 1). W 2010 r. wszystkie testowane środki nieskutecznie chroniły astra odmiany Srebrzysta Gwiazdka przed porażeniem liści i pędów, choć najmniej objawów chorobowych zaobserwowano w kombinacji z preparatem Amistar 250 SC. Dla astrów odmiany Duszek skutecznymi były preparaty: Amistar 250 SC, Polyversum WP i Prev-B2. Dla odmiany Skrzat istotnie wpływały na ograniczenie wystapienia objawów chorobowych na zielonych częściach roślin tylko środki Amistar 250 SC i Polyversum WP. W 2011 r. na roślinach odmiany Duszek nie zauważono istotnego wpły- wu wszystkich testowanych preparatów na zdrowotność liści i pędów. Dla astra odmiany Skrzat najskuteczniejsze do ochrony zielonych części przed chorobami były preparaty Amistar $250 \mathrm{SC}$ i Polyversum WP, natomiast dla odmiany Srebrzysta Gwiazdka skutecznym okazał się tylko Amistar 250 SC (rys. 1). Dużą skuteczność preparatu Polyverum WP potwierdziła Patkowska (2006) w ochronie grochu i bobu przed patogenami grzybowymi.

\section{Wnioski / Conclusions}

1. Najwięcej zmian chorobowych podczas obu lat doświadczeń zaobserwowano na odmianie Duszek.

2. Preparaty Amistar $250 \mathrm{SC}$ oraz Polyversum WP skutecznie ograniczały zamieranie całych roślin.

3. Amistar 250 SC, Prev-B2 i Polyversum WP wpływały na zmniejszenie występowania zmian chorobowych zarówno na liściach, jak i na pędach astrów.

4. Zastosowanie preparatów Amistar 250 SC oraz PrevB2 hamowało rozwój zgorzeli kwiatostanów.

\section{Literatura / References}

Horst R.K. 2008. Westcott's Plant Disease Handbook. Springer Verlag, Berlin, Heideberg, New York, 1317 pp.

Nawrocki J. 2008. Wpływ wybranych preparatów na zdrowotność i plon bulw mieczyka ogrodowego. Zesz. Probl. Post. Nauk Rol. 529: $103-108$.

Necas T., Kobza F. 2008. Resistance of Chinese aster (Callistephus chinensis Nees.) to Fusarium wilts (Fusarium oxysporum f. sp. callistephi (Beach) Snyder and Hansen) evaluated using artificial inoculations. Hort. Sci. 35 (4): 151-161.

Orlikowski L.B., Saniewska A. 1988. Influence of some enviromental factors on the population density of Fusarium oxysporum f. sp. callistephi in soil. I. Occurrence of Fusarium oxysporum f. sp. callistephi and F. oxysporum on aster plants and in soil. Prace ISiK Skierniewice, Rośliny Ozdobne, B, 12: 177-180.

Patkowska E. 2006. Effectiveness of grapefruit extract and Pythium oligandrum in the control of bean and peas pathogens. J. Plant Prot. Res. 46 (1): 15-28.

Saniewska A. 1991. Przyczyny więdnięcia i zamierania astrów chińskich (Callistephus chinensis (L.) Ness) w Polsce. Prace ISiK Skierniewice, Rośliny Ozdobne, B, 16: 171-180.

Saniewska A., Orlikowski L., Karpiński S., Rzepkowska A. 1992. Ocena odporności odmian astrów chińskich na Fusarium oxysporum f. sp. callistephi (Beach) Snyd. et Hans. Prace ISiK Skierniewice, Rośliny Ozdobne, B, 17: 99-106.

Saniewska A. 1993. Chemiczna ochrona astrów letnich przed Fusarium oxysporum f. sp. callistephi. Zesz. Nauk. ISiK 1: 119-126.

Saniewska A. 2001. Możliwości wykorzystania biopreparatu Polyversum w ochronie astrów chińskich przed Fusarium oxysporum f. sp. callistephi. [Possibilities of using biopreparate Polyversum in the protection of Chinese aster against Fusarium oxysporum f. sp. callistephi]. Prog. Plant Prot./Post. Ochr. Roślin 41 (2): 798-801.

Saniewska A. 2006. Wpływ endogennych flawonoidów grejpfruta (Citrus paradisi Macf.) na wzrost i rozwój dwóch form specjalnych Fusarium oxysporum Schlecht. [Influence of grapefruit (Citrus paradisi Macf.) endogenic flavonoids on the growth and development of two special forms Fusarium oxysporum Schlecht]. Prog. Plant Prot./Post. Ochr. Roślin 46 (2): 517-520.

Seema M., Devaki N.S. 2010. Effect of some essential oils on Rhizoctonia solani Kuhn infecting flue-cured Virginia tobacco. J. Biopest. 3 (3): $563-566$.

Segarra G., Casanova E., Aviles M., Trillas I. 2010. Trichoderma asperellum strain T34 controls Fusarium wilt disease in tomato plants in soilless culture through competition for iron. Microb. Ecol. 59 (1): 141-149.

Wilson C.L., Solar J.M., Ghaouth A.L., Wisniewski M.E. 1997. Rapid evaluation of plant extracts and essential oils for antifungal activity against Botrytis cinerea. Plant Dis. 81 (2): 204-210. 